\title{
The impact of organisational factors on career pathways for female coaches.
}

\author{
Jeff Greenhill \\ Centre of Excellence for Applied Sport Science Research \\ Queensland Academy of Sport \\ PO Box 956 \\ Sunnybank QLD 4109 \\ Ph: 61738720272 \\ Fax: 61738720205 \\ Email: Jeff.Greenhill@srq.qld.gov.au \\ Professor Chris Auld \\ Griffith Business School \\ Griffith University \\ Nathan Campus, 170 Kessels Road, \\ Nathan Queensland 4011 Australia \\ Ph: 61737356641 \\ Fax: 61737354090 \\ Email: c.auld@griffith.edu.au \\ Professor Graham Cuskelly \\ Griffith Business School \\ Griffith University \\ Gold Coast Campus, Parklands Drive, \\ Southport Queensland 4215 Australia \\ Ph: 61755528472 \\ Fax: 61755528469 \\ Email: g.cuskelly@griffith.edu.au \\ Dr Sue Hooper \\ Centre of Excellence for Applied Sport Science Research \\ Queensland Academy of Sport \\ PO Box 956 \\ Sunnybank Qld 4109 \\ Ph: 61 (7) 38720218 \\ Fax: 61 (7) 38720205 \\ Email: Sue.hooper@srq.qld.gov.au
}




\title{
The impact of organisational factors on career pathways for female coaches.
}

\begin{abstract}
Government and sport organisations have spent considerable resources on increasing the number of female coaches in sport, yet women are still significantly under-represented in this sector. Research directed towards understanding why females remain involved in coaching in the Australian sport system has tended to focus on individual barriers and motivations, with generally less attention given to the organisational setting in which coaches work. To examine why there continues to be low numbers of female coaches in elite sport, Kanter's (1977) organisational theory of homologous reproduction was used to guide a case study of a state sport organisation (SSO). Results indicated that organisational strategies, prevailing hegemonic masculinity, and systemic barriers in the SSO were sustaining male coaching dominance in the organisation while marginalizing women.
\end{abstract}




\section{Introduction}

Behind the highly publicized international success of Australian athletes and teams is a problematic feature of the Australian sport system. Despite the dependence of organised sport on the continued availability of coaches, coach numbers have been erratic. The Australian Sports Commission (ASC) noted that Australia recorded a 7.2\% fall in the number of accredited coaches in 2002-2003 and this was followed by a $9.6 \%$ reduction in 2003-2004 (ASC, 2003, 2004). A major review of the national coach accreditation scheme (NCAS) in 2003-2004 eventuated in the ASC developing a new database to record the number of accredited coaches and sports no longer being required to adhere to a Level 1 to 3 structure. Since this change, national sport organisations (NSOs) determine the number, name and level of accreditation that best suits each sport. This has led to more NSOs registering with the NCAS and a number revising their accreditation structures. Subsequently, the ASC recorded a 7.7\% increase in the number of accredited coaches in 2004-2005, followed by a $41.9 \%$ increase in 2005-2006, and a 10.5\% increase in 2006-2007 (ASC, 2005, 2006, 2007). Given the significant changes within the NCAS structure over this time, it is difficult to ascertain reasons for recent increases, and they may only reflect a change in how coach numbers are measured. Of

concern however, is the continued low number of female coaches, especially at the elite level (Peters, 2006).

This concern is centred not only on equal opportunity for women, but also on availability of female role models for young people (Fox, 1999; Peters, 2006; Roffey, 2001). The Australian Bureau of Statistics (ABS) reported that in 1993, 41.2\% (N= $219,200)$ of those involved in a coaching, instructor or teaching role in organised sport 
and physical activity were female (ABS, 2004). However, in 2004, despite an increase in the total number of coaches, females had decreased to 38.6\% $(\mathrm{N}=229,400)$. Moreover in 2006, only 36\% ( $\mathrm{N}=23,302)$ of all Level 1 accredited coaches were female and only 15\% ( $N=170)$ of Level 3 accredited coaches were female (Peters, 2006).

Despite efforts by governments and sport organisations to close the gender equity gap in coaching through programs such as the Sport Leadership Grant for Women (SLGW) offered by the ASC since November 2002, the situation has not improved and appears to be worsening. Therefore, this study focussed on why females continue to be underrepresented in sports coaching, especially at the elite level. For the purpose of this study, elite has been defined as sport played at state (provincial), national and international standards.

\section{Theoretical framework}

Research involving the domination by selected groups (usually men) in business organisations suggests that those in power maintain their control by allowing only others who share common characteristics to enter their circle of influence (Kanter, 1977). This selective process may produce networks closed to women and as a result women are frequently not considered for managerial positions (Ehrich, 1994; Kanter, 1977; Luthans, 1988; Reynolds, 1991; Schell \& Rodriquez, 2000; Sheridan \& Milgate, 2003; Whisenant, Vincent, Pedersen, \& Zapalac, 2007). This process is often referred to as the old boys’ network. The exclusion of women is not due to a lack of managerial competencies, but rather a lack of particular social characteristics.

Male hegemony (i.e., the old boys’ network) has been identified as a dominant explanation for the decline of women in coaching roles in American interscholastic 
athletics (Lovett \& Lowry, 1994; Schell \& Rodriquez, 2000; Whisenant et al., 2007). However, even though male hegemony has been used to explain gender inequality in many male-dominated industries (Bagilhole, 2000; Lorber, 1994; Ward, 2000; White, 2001), perceptions of the old boys’ network in Australian sport is one issue that has not featured prominently in research on the career progression of female coaches.

Gender equity research in sport management has traditionally been based on liberal feminist theory, which according to some authors is largely focused on increasing the numbers of women in managerial positions and "does little to challenge or alter dominant gendered discourses and power structures within sport organisations” (Shaw \& Frisby, 2006, p. 483). Furthermore, it has been argued that research informed by liberal feminism does not encourage a full examination of the assumptions, values, and beliefs about men and women that are deeply entrenched in organisations (Meyerson \& Kolb, 2000; Shaw \& Frisby, 2006). Given these concerns regarding liberal feminism, support for a shift in how it is conceptualised has grown and it has been argued that poststructural feminist theory provides an appropriate (or more effective) lens for challenging traditional thinking and envisioning the changes that are required in organisational structures and culture (Aitchison, 2000; Rao, Stuart, \& Kelleher, 1999; Shaw \& Frisby, 2006).

Other sport management authors have applied alternative organisational theories to address the inequity experienced by women in their pursuit of sports leadership positions (Knoppers, 1987). For example, a number of studies specifically focused on equity issues in coaching in the USA have applied Kanter's (1977) organisational theory of homologous reproduction (e.g., Lovett \& Lowry, 1994; Stahura \& Greenwood, 2001; 
Stangl \& Kane, 1991; Whisenant et al., 2007). Homologous reproduction is the phenomenon where the dominant coalition (i.e., men) works systematically to reproduce itself and subsequently maintains the status quo of male authority within the managerial structure of organisations (Kanter, 1977; Lovett \& Lowry, 1994; Stahura \& Greenwood, 2001; Stangl \& Kane, 1991; Whisenant et al., 2007). This theory conceptualises processes of exclusion based on social characteristics and the sustainability of hegemonic practices. LeDrew and Zimmerman (1994) stated that female coaches have their abilities undervalued by both males and females who are directly involved in coaching, as well as those who are not involved. Aside from overt discrimination, Kanter's (1977) theory of homologous reproduction is suggested as a possible means of explaining the gender gap in female leadership positions within the Australian sports system. Furthermore, given that this theory has strong similarities with post-structural feminism, applying the homologous reproduction model to Australian sport coaching may assist in explaining the constraints impacting on women pursuing coaching careers.

Knoppers (1987) was the first researcher to apply the organisational model of homologous reproduction to sports by exploring the effects of three key constructs on women in coaching: opportunity; power; and, proportion. This author reported on the vast array of obstacles inhibiting opportunity for women in coaching careers. Those obstacles associated with working in a male-dominated profession included gender discrimination, limited access to coaching boys’ sports, family role conflicts, and in some cases sexual harassment. Power was framed not as domination over others, but as the ability to collect the formal and informal resources necessary to be successful in work-related roles. The 
final element of proportion pertained to the ratio of women to men employed within the profession or organisation.

Stangl and Kane (1991) utilized homologous reproduction to determine if the gender of athletic directors was related to the proportion of male and female head coaches in their athletic departments. They found "the dominant group systematically reproduces itself in its own image” (Stangl \& Kane, 1991, p. 50) with female athletic directors more likely to hire female head coaches than male athletic directors. These findings suggested that homologous reproduction was present in interscholastic coaching in the United States. Lovett and Lowry (1994) arrived at similar conclusions, when they expanded their work to include the gender of the school principal. Their results indicated that the gender of the administrators, principals, and athletic directors affected hiring decisions, which resulted in homologous reproduction of the coaches. They also noted that while men had head coach positions on female teams, women were seldom the head coach of male teams.

Stahura and Greenwood (2001) provided further evidence showing that the gender of the athletic director influenced hiring patterns and that the head coach of a more competitively-ranked university was less likely to hire females than the head coach in a lower competitively-ranked university. However, a recent study by Whisenant and coworkers (2007) contradicted these earlier studies, finding that those in power (i.e., superintendents and athletic directors) did not hire in line with their gender and the gender of the coach or administrator. The results suggested however, that the females in athletic director roles might be in place as a matter of tokenism as the ratio of females to males was 0.016:1 (Whisenant et al., 2007). Their explanation for the skewed gender 
ratio between females and males was based on three factors: self-efficacy; absence of women coaching boys’ sports; and, how positions were advertised.

The above discussion has illustrated a number of studies that have tested the efficacy of homologous reproduction in hiring practices in the American sport system (at interscholastic and collegiate levels). However, no application of homologous reproduction theory to the Australian sports system has been reported in the literature and as there are structural differences between the Australian and American sports systems, it might not be appropriate to generalize these findings from the US studies as an explanation for the disproportion of females coaching in elite Australian sport.

Therefore, as homologous reproduction is based on the assumption that the workplace processes (i.e., management structure, recruitment and promotion procedures, and working conditions) shapes the workers in these settings (Knoppers, 1987), the current study assessed organisational practices, decision maker perceptions, and male and female coach experiences to determine their impact on career pathways for female coaches. The following research questions were addressed:

1) To what extent do organisational career development strategies affect female coach career progression?

2) To what extent do the perceptions of decision makers affect the career progression of female coaches to the elite level?

3) To what extent do decision makers’ perceptions about career development techniques for male and female coaches differ? 


\section{Related Literature}

\section{Career pathway barriers}

Numerous authors have sought to explain why there are low numbers of female coaches at the elite level of sport. Two Australian studies (Fox, 1999; Roffey, 2001) provide some direction with reference to specific factors that impinge on female participation in coaching. Both authors interviewed female coaches to find out what motivational and structural issues affect the coaching profession. Fox (1999) interviewed ten female coaches from five sports whilst Roffey (2001) surveyed and held open forums for female coaches, also from five different sports. Time pressures, lack of compensation, lack of opportunity, discrimination, and perceptions of a strong 'old boys' club’ were cited as common barriers by both authors. Furthermore, Roffey (2001) concluded that when the benefits of coaching are weighed against the perceived negatives, coaching was often viewed as a career that offers little reward for a lot of personal expenditure.

This conclusion is similar to that of psychologists explaining gender inequality in coaching (Weiss \& Stevens, 1993). These authors investigated the motivation and attrition of female coaches in the USA using social exchange theory. The basis of social exchange theory is that behaviour is motivated by the desire to maximise positive and minimise negative experiences through social interactions (Weiss \& Stevens, 1993). Therefore, if females were experiencing negative experiences through social interactions during their coaching careers from barriers such as the “old boys' club”, a career in coaching would seem to offer little reward.

A strength of the findings provided by Fox (1999), Weiss and Stevens (1993), and Roffey (2001), is that common issues and barriers confronting female coaches were 
identified from separate methodologies. However, Fox’s (1999) methods may be limited in that only ten currently coaching females were interviewed and none who had left the profession. Roffey (2001) conducted her research through open forums and surveys to current and past coaches but only gathered data from females. Neither study explored the perceptions of male coaches to see if a distinction exists between genders. Male coaches may experience similar barriers in their career pathways, indicating that some of the authors' findings are not issues of gender as proposed. Additionally, neither study included information from other key sources such as sport administrators.

\section{Hegemonic masculinity and the old boys' network}

The systemic barriers (in both the minds and actions of participants) that sustain sport as a male institution, while marginalizing women, represents hegemonic masculinity (Schell \& Rodriquez, 2000; Whisenant et al., 2007). Whether through overt or covert discrimination, hegemonic masculinity results in constraints that reinforce the acceptance of masculinity as the defining characteristic within an occupation or culture and supports the proposition that females in western society are consigned to genderappropriate roles (Connell, 1987; Kane \& Disch, 1993; Schell \& Rodriquez, 2000; Ward, 2000; Whisenant et al., 2007).

Sheridan and Milgate (2003) explored factors contributing to low representation of female board members on publicly listed company boards and found that females and males have different views on the homogeneity of board membership. Their findings indicated that those who are part of the hegemonic group do not question the structures that sustain that hegemony. Whilst male hegemony has been used to frame the existence of old boys' networks in management in Australia (Sheridan \& Milgate, 2003) it has also 
been used to describe similar processes in sport in the United States (Lovett \& Lowry, 1994; Schell \& Rodriquez, 2000; Whisenant et al., 2007).

Engaging in networking activities has been shown to have a positive influence on career progression in sport (Whisenant \& Pedersen, 2004), just as it does in traditional business settings (Luthans, 1988). In addition, various authors (Knoppers, 1987; Lovett \& Lowry, 1994; McKay, 1997; Schell \& Rodriquez, 2000; Thorngren, 1990; Whisenant et al., 2007) have stated that discrimination and the old boys' network are more likely to be perceived by female coaches rather than males, and that these perceptions have subsequently impacted on female careers. Ehrich (1994) has also suggested that it is easier for males than females to access power through mentoring and networking as these are traditionally male dominated practices. Moreover, Whisenant and Pederson (2004) concluded that:

While networking can be a powerful tool which individuals can use to move up the ranks of intercollegiate athletics, it can also work against those (i.e., women) not privileged to its power (p. 25).

Although many scholars have examined gender inequalities in management in sporting organisations including the dynamics and power of networking, research has predominantly used survey methods. However, McKay (1997, p.10), used empirical research in an attempt to make hegemonic masculinity “visible” (i.e. “to articulate men’s identities and power as men in organizations that they generally assume are genderless”) by comparing the managerial experiences of both men and women in sport organisations with androcentric cultures. 
Similarly, the present study assessed the experiences of males and female coaches and administrators using a case study approach to determine the impact organisational factors have on career pathways for female coaches.

\section{Methodology}

\section{Protocol}

This research used a holistic single case study of a Queensland state (provincial) sporting organisation (SSO). The criterion used in selecting the SSO was that the organisation should represent the disproportion of female coaches in a sport that had a gender-neutral participant base (i.e., neither male nor female dominated). Using this criterion, three SSOs were identified and the Queensland Academy of Sport (QAS) facilitated access to these organisations. An SSO with a low proportion of female coaches at the elite level and the most equal representation of gender in participants was selected by the researcher for the critical case. The SSO is not named for privacy and confidentiality reasons.

Three data sources were used in this study: qualitative semi-structured interviews utilising open ended questions; organisational documents; and, archival records. Organisational documents included strategic plans, annual reports, coaching manuals, and position descriptions. Archival records included newspapers and information from the SSO's website. Although organisational documents were also sourced from the SSO's website, the majority of documents were received from administrators and coaches during interviews. 
Interviews were conducted at a time and location convenient to respondents. The interviewees were under no obligation to participate in the study and volunteered their time freely. An interview schedule was used to guide the semi-structured interviewing process for consistency and focus. The format allowed the interviewer to have some control over the direction of the discussion whilst allowing the interviewee to elaborate on further areas of interest. Participants were initially asked to indicate their role and provide some background information on their involvement in sport and experiences with the SSO. Knoppers’ (1987) structural determinants of homologous reproduction (opportunity, power, proportion) framed the subsequent questions to coaches and administrators on career pathways for coaches and organisational strategies to recruit, develop, and retain coaches. After a preliminary interview with the SSO General Manager, interview questions were extended to include communication strategies, external support (such as ASC grants and programs), and issues regarding the influence of gender on career progression.

\section{Sample}

Interviewees were determined via meetings with the SSO General Manager and the QAS high performance manager of the sport studied. The General Manager provided contact information for coaches and administrators and distributed an email of support for the research to all coaches in the organisation asking interested persons to contact the researcher. The QAS high performance manager provided further assistance by providing an external prospective on the sport organisations structure and administration. The researcher subsequently contacted eight individuals (four males and four females) for interviews and six accepted (one administrator, one administrator who also coached at 
state level, two state level coaches, one ex-state level coach, and the QAS coach of the sport). Administrators had a mean of 3 years experience in their current sport administrative roles, whilst coaches had a mean of 19.3 years experience in coaching. Two women and four men were included in the sample. No female administrators were employed by the SSO and thus none could be included in the sample. Table 1 shows the interview sample by gender and position.

Table 1

Interview sample by gender and position

\begin{tabular}{|c|c|c|c|c|c|}
\hline \multirow[b]{2}{*}{ Gender } & \multicolumn{4}{|c|}{ Position } & \multirow[b]{2}{*}{ Tota } \\
\hline & Administrator & Coach & Ex-coach & $\begin{array}{l}\text { Administrator } \\
\text { and coach }\end{array}$ & \\
\hline Male & 1 & 2 & & 1 & 4 \\
\hline Female & & 1 & 1 & & 2 \\
\hline Total & 1 & 3 & 1 & 1 & 6 \\
\hline
\end{tabular}

Interviews were recorded by a digital audio recorder, downloaded onto a hard drive and replayed with the use of Express Scribe software to transcribe interviews. Participants were supplied with their individual interview transcriptions to check accuracy of transcriptions. 


\section{Data analysis}

The analytic strategy was underpinned by the theoretical proposition of homologous reproduction of gender inequality in organisations. To this end, information was analyzed to determine the extent to which the three structural determinants of homologous reproduction influenced career pathways for female coaches in the SSO. Data units (key responses from the transcribed interviews) were identified and subjected to content analysis. This involved coding the data to extract the underlying themes from the interviews.

Interview data were coded into open, axial and reflective codes for thematic analysis. After several phases of response coding, emerging themes reached saturation. During the coding process, constant comparison was used, requiring the researcher to continuously revisit and redefine the open and axial codes. Additionally, the codes were checked by a highly experienced coder and assessed for consistency. Three key themes emerged: coach attributes; coaching environment; and, coach networks.

Additional analysis was also conducted on the organisational documents and archival records:

- 2006 annual report;

- 2006 and the 2007 strategic plans;

- coaching accreditation level manuals;

- coaching newsletters;

- coaching position advertisements;

- state level coaching position descriptions; and, - coaching databases sourced from the SSO. 
Data were subjected to content analysis to investigate themes from the interviews. This analysis was then triangulated with thematic analysis of interview data to produce a narrative of findings. Due to the depth and richness of responses and opinions gained from the interviews, the majority of the analysis and discussion focuses on the data derived from the semi-structured interviews. Interview data have been triangulated with the results from the analysis of the archival data and organisational documents which were used to support or refute findings stemming from the interview data.

\section{Results}

In the interviews, participants were asked to consider issues related to career pathways for female coaches. The three major themes which emerged from the analysis of interview data are illustrated in Figure 1. 
Figure 1. Factors affecting career pathways for female coaches in the SSO.

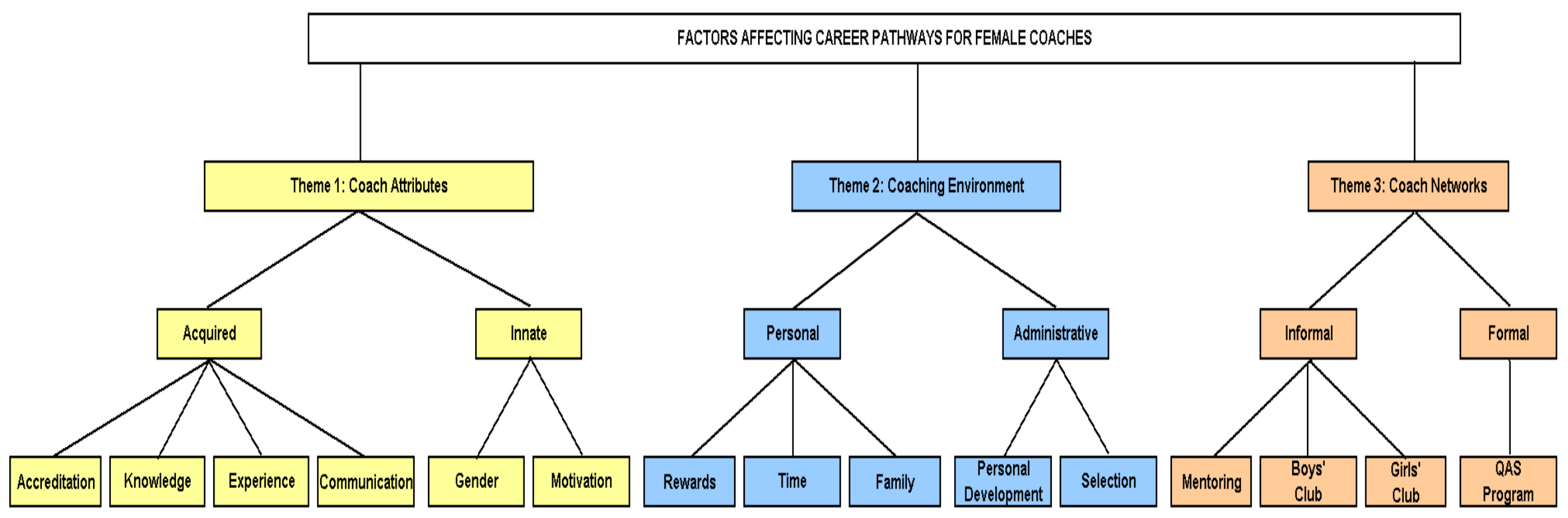


Career pathways for female coaches are influenced by three main themes:

1) elite coach attributes considered important by coaches and administrators;

2) the coaching environment and support available to coaches; and,

3) availability of formal and informal networks to coaches.

Not all participants discussed each of the factors associated with a theme, illustrating the diversity of individual experiences and opinions in the SSO. Each of the themes will now be discussed.

\section{Coach attributes}

A coach attribute relates to both the acquired and innate qualities that coaches and administrators indicated were needed by coaches to progress their careers to the elite level. Acquired attributes relate to accreditation, communication skills, knowledge and experience, whereas innate attributes are qualities relating to motivation and gender. Whilst administrators and coaches agreed on many attributes considered important (e.g., high motivation and communication skills), opinions differed on the definition and parameters of these factors. In addition, views about the importance of other attributes such as accreditation, knowledge and experience, also varied between males and females. Furthermore, placing coaches in gender appropriate roles emerged as a dominant issue and opinions varied greatly amongst respondents.

Organisational documents such as position descriptions, job advertisements and key selection criteria for elite positions reflected the attributes the organisation perceived as requirements for coaches to be successful in their roles. These attributes included

formal coaching accreditation, knowledge and experience of coaching and high level communication skills. The SSO had in place a number of initiatives to encourage 
individuals to develop their careers such as: online coaching handbooks on the SSO website; accreditation development clinics; and, coaching conferences and camps.

While both male and female coaches placed high importance on having the required coaching accreditation levels in order to apply for elite positions, male coaches indicated that experience was the key factor in gaining these positions. However, the female coaches did not mention this factor. The two female coaches indicated that they would not apply for higher coaching positions unless they had the required accreditation level, even if their experience was extensive and they thought they could do the job. When administrators were asked for clarification on the weighting of criteria in assessing potential coaches, they indicated that some attributes were more essential than others. For example, coaching experience was considered more valuable than formal coaching accreditation levels when assessing applicants for elite teams.

Motivation also emerged as a dominant issue for coach attributes. Key selection criteria for elite coaching roles listed 'needs to be highly motivated' as a requirement for the positions and administrators confirmed that this was a key attribute of successful coaches. However, this study found a discrepancy among interviewees on what is implied by 'needs to be highly motivated'. Male administrators and male coaches felt that highly motivated coaches are coaches who "place winning above all else" (Administrator 1) and "sacrifice a great deal for the success of the team" (Male Coach 3). In contrast, female coaches felt that highly motivated implied being "passionate about the development of the kids" (Female Coach 1) and "being a (sport) junkie and wanting to give back to the sport I love” (Female Coach 2). 
Another dominant issue that emerged from the study was gender roles. The administrators (both males) had dissimilar views about the placing of coaches in roles according to their gender and the gender of the team. One administrator stated that gender was not a factor in deciding who is selected for a coaching position, nor did he think that coaches would identify themselves as a specialised male or female coach.

"I don't think that we value male or female coaches any more than each other; it's the person with the most experience, the right person for the right job." (Administrator 1)

However, the other administrator stated that the SSO preferred to have female coaches for female teams to provide role models for other females.

"We try to appoint female coaches for female teams... preferentially we would like a female coaching female and male coaching male. Logistically it's a lot easier and I think it's........, we'd like to you know, create more role models for our female players and coaches.” (Administrator 2)

This difference in opinions between administrators indicated that some of the informal selection policies of the SSO might not have been well discussed within the organisation.

\section{Coaching environment}

This study found that two broad areas influence the coaching environment: the administrative environment of the SSO and the personal support environment of the coach. The administrative environment was considered to be affected by selection processes of coaches and the development opportunities made available to coaches. The personal environment was considered to be affected by the rewards received for 
coaching, time pressures, and the psychological and emotional influence of people outside the sport organisation (e.g., family).

Male and female coaches both indicated that low numbers of female coaches is an issue of concern and that more female coaches were required in order to provide role models for younger female athletes and thereby increase the number of participants in the sport. However, administrators believed that the proportion of female coaches in the sport was relatively equal to the proportion of female participants although this was not supported by the SSO's annual report which showed female participants represented just over $45 \%$ of the total member base in 2006. In contrast, the SSO's coaching database indicated that $28 \%$ of coaches were female.

Coaching development grants and level of support given to coaches were considered a key issue for career pathway development. However, one administrator commented when asked if the SSO promoted career development programs such as the Australian Sports Commission (ASC) Sport Leadership Grant for Women (SLGW) to their female coaches:

“We don't offer them at the moment because we're trying to treat everyone the same. So if we're going to give coaching scholarships out, it would be to the best coach, or the most potential - whether they be male or female. We don't discriminate one-way or another. I know there are a lot of grants available for women; but you know, realistically this is a two gender sport and we want to keep it that way.” (Administrator 1)

Family commitments and lack of time also emerged as dominant issues in coaching career development. Both male and female coaches reported that the time 
demands of coaching put a great deal of strain on their personal lives. The administrators agreed that coaching was taxing on coaches' time but they had not instigated any organisational processes to deal with this. Female coaches, more than male coaches, indicated that family responsibilities negatively affected their ability to develop their coaching careers.

Another environmental issue discussed by interviewees was remuneration. Coaching positions in the SSO studied were all voluntary. Therefore, coaches do not receive any remuneration except for reimbursement for expenses associated with travelling to competitions. Administrators felt that this may be a factor that greatly affected the number of elite coaches within the organisation.

"It's a thankless job. If we could afford to give them some sort of money then I think we could increase the number of females coaching and the sport would be better off." (Administrator 1)

Female coaches indicated that although they felt coaching positions were often undervalued and under-rewarded, money would not be a factor in increasing the number of female coaches at elite levels.

"I think money can be dangerous...I think people do deserve some credence for the work they do they need to be acknowledged. If you're in coaching only for money and not in there for kids...It's a thankless job but I think coaching it's 99.9\% for the development of kids." (Female Coach 1)

Male coaches also stated that remuneration was not a factor in deciding to develop their careers and they felt that they were rewarded and received thanks for volunteering their time. However, the female coaches did not report this feeling. 


\section{Coach networks}

The results of this study indicated that networking has a large impact on female coaching career development and consequently the numbers of females coaching at the elite level. It is important to note that networking is also embedded in most, if not all, of the factors associated with the other identified themes in this study. For example, consider the coach attributes theme discussed above, an administrator indicated that coaches do not always require accreditation to gain elite positions as they "come through the network that they have already made during their playing time" and experience was highly valued. Coaches benefit from the generic informal networks that they are a part of prior to entering coaching as well as formal networks that are facilitated for them. Informal network dynamics discussed by interviewees in this study were girls’ clubs, boys' clubs and informal mentoring programs, whilst the only formal network mentioned by the interviewees in this study was the Queensland Academy of Sport (QAS) coaching development program.

Informal mentoring programs for talented female coaches emerged as an important issue. Female coaches stated that they have been taking it upon themselves to mentor female athletes who show an interest in coaching. This is illustrated in a comment made by a female coach interviewee:

"I think it's different for a female coach, especially if there are males in charge of something and they want their mates in there. (The SSO) doesn't have any development programs in place for girls in particular, so I have mentored before..... .like young kids that want to coach, but not officially, you just do it as a way of career coaching.” (Female Coach 1) 
This study also found that informal networks such as the presence of a boys' club in the SSO is a distinct disadvantage for females, as illustrated by a female coach:

"I think it's easier for males, I think it really is a lot easier, it's a bit of a boys' club, but I think that's in any sport. But the females, if you're prepared to do it, and if you have results they don't knock you back, not in (the SSO) anyway." (Female Coach 2)

Unlike male and female coaches, administrators did not feel that a boys' club existed within the organisation nor did they feel that females were disadvantaged in comparison with males in gaining coaching positions.

Another informal network that impacts upon female coaching career pathways is the girls' network. Similar to boys’ clubs, a girls’ network consists of females (e.g., administrators and coaches) helping and supporting each other. An administrator indicated that the coaching and education director of a major regional centre was female and since her appointment the region had increased its proportion of female coaches to males more so than other regions in the state. The administrator went on to state that he felt the increased promotion was needed in the past as the number of women in coaching was very low but he now feels that the "organisation has passed that boys' club mentality” and female coach numbers were adequate.

\section{Discussion}

The purpose of this study was to investigate why females continue to be underrepresented in sports coaching, in particular, at the elite level of sport. By assessing 
organisational practices, decision maker perceptions, and male and female coach experiences, three main themes were identified that impact on career pathways for female coaches. These themes (coach attributes, coaching environment and coach networks), illustrate the dynamic environment in which coaches work and some of the difficulties that females face in pursuit of elite positions. Three research questions were posed for this study and each of these will now be discussed considering these themes. This discussion also draws on existing literature to further clarify these findings and present an evaluation of the use of homologous reproduction theory to Australian sport coaching. Finally, the limitations of the study are presented with recommendations for further research in this area.

The first research question posed for this study was to determine to what extent organisational career development strategies affect female coach career progression. Time and family commitments emerged as a dominant issue with respondents indicating that the demands of coaching negatively affected their time spent with family and vice versa. Previous research on work-family role conflicts has suggested that women struggle for power and a voice in work scheduling in male-dominated industries and that these industries are usually less well developed in their work-family policies (Dixon \& Bruening, 2006; Goodstein, 1994; Inglis, Danylchuk, \& Pastore, 2000; Milliken, Martins, \& Morgan, 1998). Given that female coaches, more than males, indicated that family responsibilities negatively affected their coaching careers, incorporating formal workfamily policies into organisational career development strategies may be useful for female coach career development. 
Additionally, it seems that the organisation's formal processes of elite coach recruitment and promotion, such as position advertisements and key selection criteria, are perhaps less likely to attract females. For example, the two female coaches indicated that they would not apply for higher coaching positions unless they had the required accreditation level, even if their experience was extensive and they thought they could do the job. The male coaches interviewed did not share this belief. Furthermore, administrators indicated that some criteria were more essential than others and that experience was regarded as being more important than accreditation when assessing elite coach applicants. By placing greater emphasis on accreditation in assessing their own suitability for elite coach positions, it appears that females may be discounting their own ability to be successful in the recruitment process and therefore are not making themselves available for these positions.

Additionally, it seemed that formal coaching applications submitted by males are more likely to appeal to selectors than those of females, as the male coaches interviewed were more congruent with the perceptions of administrators on what constitutes high motivation. This may be due to male coaches gaining informal knowledge through their networks with male administrators in the SSO. This is consistent with previous research in the business literature indicating that males have more access to informal information through networks when they are the dominant group (Davies-Netzley, 1998; Ehrich, 1994; Fink \& Pastore, 1999). Therefore, organisational strategies appear to have a negative affect on females in the sport environment inhibiting the number of females moving through to elite levels of coaching due to prevailing hegemonic masculinity in the sport organisation. 
The second research question examined to what extent the perceptions of decision makers affect the career progression of female coaches to the elite level. The difference between administrators and coaches' perceptions on remuneration may be a key factor influencing the coaching environment and subsequently career pathways for females. The comments expressed by coaches on rewards from coaching indicate that they are true volunteers and expect no financial gain from coaching. The administrators may have had a different perspective on rewards for coaches as they were in paid positions in the SSO and thus were likely to have different personal motives and expectations for being involved in the sport. By placing greater emphasis on the lack of monetary awards as a reason for low numbers of elite female coaches, it seems that administrators may have been neglecting important rewards that female coaches feel are lacking (i.e., recognition and words of appreciation).

The administrators interviewed did not perceive an old boys’ network to be affecting coaching career pathways for females nor did they believe that the low number of females coaching in the sport was of concern. Similar to Sheridan and Milgate (2003) these findings suggest that whilst the females were concerned about the lack of gender diversity in the organisation, the males in positions of power believed the current composition was adequate. These findings support the proposition that those who are part of the hegemonic group do not question the structures that sustain that hegemony (Knoppers, 1987; Lovett \& Lowry, 1994; Schwalbe et al., 2000; Sheridan \& Milgate, 2003; Stangl \& Kane, 1991; Whisenant et al., 2007). Similar to the conclusion of Whisenant and Pederson (2004), this study found that while networking is a very powerful way for individuals to develop their careers to elite levels of coaching, it can 
also work against those (i.e., female coaches) not privileged to its power. According to Pini, Brown and Ryan (2004), women-only networks have a valuable role to play in securing greater equity for women in management. Assigning mentor coaches to lower level coaches may create the networks and confidence that females require to be successful in their careers. Interviewees supported this proposition and had been unofficially mentoring female coaches to keep them involved in the sport.

However, if more females are able to gain senior positions in the SSO where they can affect organisational change and support other females, it is more likely that shifts in the perceptions of male dominance in this sport will occur (Kerr \& Marshall, 2007; Schwalbe et al., 2000). To achieve this, it has been suggested that a change in culture both within the organisation and in the wider community is required (Kerr \& Marshall, 2007; Schwalbe et al., 2000). In summary, although the views of administrators on the rewards and recognition for coaches and the proportion of female coaches in the SSO suggested that administrator's perceptions were affecting the career progression of females to the elite level, the extent to which this is occurring is not evident from the data.

The final research question posed for this study was to determine to what extent decision makers' perceptions about career development techniques for male and female coaches differ. A common concern for the two administrators was that development programs for female coaches discriminated against male coaches. This is consistent with previous research in the business literature indicating that males in positions of power have perceived affirmative action programs as "institutionalised discrimination against men rather than as an anti-discrimination program” (Leonard, 1989 p.61). The Coaching 
Association of Canada (CAC) (2007) suggests that reverse discrimination implies that the status quo is fine for now and that change will come naturally and slowly over time. Many authors in business and in sport have suggested that specific programs targeted at women are needed to increase gender equity in organisations and eliminate imbalances supported by outdated traditions (Knoppers, 1987; Leonard, 1989; Lovett \& Lowry, 1994; Schwalbe et al., 2000; Shaw \& Frisby, 2006; Stangl \& Kane, 1991; Whisenant et al., 2007).

Neither of the female coaches interviewed were aware of grants available to them, such as the SLGW, and it seemed that administrators did not promote these programs to females, as they were not fully aware of the benefits and also felt that these programs were not fair to the males in their organisation. The data indicate that the decision makers did not perceive any difference in male and female coaching abilities and therefore they did not promote any development programs to one gender more than the other. Given the low number of female coaches and female role models in the SSO studied, it is suggested that programs targeted specifically at the female coaches would be helpful (CAC, 2007; Leonard, 1989). Furthermore, promotion of these programs should highlight the benefits to both the coach and the sport organisation to increase administrator's awareness and support of initiatives.

\section{Reflection on theory}

An interesting finding of the study is the grouping of differences in opinions. By using homologous reproduction as a theoretical framework it was expected that a difference in opinions would be found between genders. In contrast, male and female coaches collectively had different opinions to SSO administrators on a number of the key 
themes identified in the study. Many differences in opinions were based on positions held within the organisation rather than gender. This may suggest that given the advances in equity practices since 1977 when homologous reproduction was originally conceptualised by Kanter, this theory may no longer be as appropriate to describe systemic barriers in an organisation by hegemonic practices based purely on gender. Rather the theory might be expandable to the hegemonic practices of organisational administrators based on their persona. Therefore male coaches who do not share the same beliefs as male administrators may not be as successful as female coaches who do share the beliefs of administrators and vice versa.

The only other study found related to sport to support this proposition is by Boutlier and SanGiovanni (1994) who suggested that the maintenance of the status quo goes beyond demographics and that homologous reproduction exists in attitudes, values, and priorities among those in leadership positions. This suggests that homologous reproduction theory does not only account for the low number of female coaches at elite levels of sport, but can also help explain how female coaches at the elite level have broken through the glass ceiling. The glass ceiling is distinguished from formal barriers to advancement, such as education or experience requirements and relates to the informal processes and policies that make up the culture of an organisation (Kerr \& Marshall, 2007; Schwalbe et al., 2000). An example of this is provided outside the sport context by Davies-Netzley (1998) who explored perceptions on corporate mobility and strategies for success for women in upper level management positions. She found that women emphasized the importance of social networks and peer similarities for succeeding in elite positions. Furthermore, women attempted to strategically increase their cultural capital to 
negotiate male dominated networks and maintain their high status positions through such measures as obtaining advanced educational degrees or modifying speech and behaviour (Davies-Netzley, 1998). The present study found that the reproduction of male coaches as the dominant group in the SSO was based on the implicit and informal beliefs of the administrators rather than gender networks; therefore females may be adapting their behaviour to accommodate administrators' beliefs. These informal beliefs according to Kerr and Marshall (2007) help define an organisation’s culture.

\section{Limitations and recommendations for future research}

There are several limitations to this study. First, the study was confined to a concise time frame and the single case study method chosen meant that the researcher was restricted to interviewing only a small number of coaches and administrators. Further, there were some contradictory responses by the administrators and more time would have allowed these to be investigated in more depth.

When the SSO was selected for this study it was not known that all coaching positions in the organisation were voluntary therefore care must be taken in generalising the findings to paid coaches. According to Graham (2004), volunteering as a leisure pursuit suggests motives to volunteer are informal and as such volunteers cannot be controlled in the same was as paid staff. This study therefore provides some insight into the role conflict of administrators and volunteer coaches which could be investigated through further research and comparison to paid coaches.

Many other opportunities for future research have been identified from the insights gained in this study. For example, the themes uncovered from interviews could be used to develop a questionnaire for a large study to more completely understand 
organisational factors that influence the career progression of female coaches.

Furthermore, the study could be extended to include an analysis of the disproportion of female administrators in sport organisations as this was found to be a key factor affecting the careers of elite female coaches. Additionally, by studying factors impacting on career pathways for female coaches this study has highlighted the issue of clearly identifiable and accessible career pathways for all coaches, regardless of gender. This too could be considered for further investigation.

\section{Conclusion}

This study has used homologous reproduction as a theoretical framework to examine sport in a new context (Australian sport coaching), which identified coaching attributes, environment, and networking as three major themes that affect female coaching career development. The findings indicated that there were systemic barriers in the SSO that sustain the institution as a stronghold of men while marginalizing women, supporting the presence of homologous reproduction. It is suggested that these systemic barriers are deeply embedded in organisational culture and due to the difficulties in changing organisational culture there may not be a generic solution to this problem. What works for one SSO may not work for another as each may have unique factors that impact on career progression for females. However, this study may provide a useful analytical tool for other sport organisations to achieve greater gender equity in sport coaching. This research was conducted with the intention to assist in improving gender equity in sport coaching and therefore provide the needed role models for young females to stay in sport. It is hoped that this analysis has provided an impetus for further research in this area. 


\section{References}

Australian Bureau of Statistics, (2006). Involvement in organised sport and physical activity Retrieved 01 October, 2007, from http://www.abs.gov.au/Ausstats/abs@.nsf/lookupMF/751BF8F6B90522DECA25 68A90013936C

Aitchison, C. (2000). Post-structural feminist theories of representing others: A response to the "crisis" in leisure studies' discourse. Leisure Studies, 19, 127-144.

Australian Sports Commission, (2003). Annual Report 2002-2003. Canberra: Australian Sports Commission.

Australian Sports Commission, (2004). Annual Report 2003-2004. Canberra: Australian Sports Commission.

Australian Sports Commission, (2005). Annual Report 2004-2005. Canberra: Australian Sports Commission.

Australian Sports Commission, (2006). Annual Report 2005-2006. Canberra: Australian Sports Commission.

Australian Sports Commission, (2007). Annual Report 2006-2007. Canberra: Australian Sports Commission.

Bagilhole, B. (2000). The Myth of Superman: A Feminist Investigation of Academic Careers. Paper presented at the 2nd European Conference on Gender Equality in Higher Education.

Boutlier, M. A., \& SanGiovanni, L. F. (1994). Politics, public policy, and Title IX: Some limitations of liberal feminism. Champaign, Illinois: Human Kinetics. 
Coaching Association of Canada, (2007). Women in Coaching. Retrieved 08 March, 2007, from http://www.coach.ca/eng/women/index.cfm

Connell, R. W. (1987). Gender and power. Stanford, CA: Stanford University.

Davies-Netzley, S. A. (1998). Women above the Glass Ceiling. Gender and Society, 12(3), 339-355.

Dixon, M.A., Bruening, J.E., (2006). Retaining Quality Workers: A Case Study of WorkFamily Conflict. Sport Management Review, 9, 79-103.

Ehrich, L. C. (1994). Mentoring and Networking for Women Educators. Women in Management Review, 9(3), 4-10.

Fink, J. S., \& Pastore, D. L. (1999). Diversity in sport? Utilizing the business literature to devise a comprehensive framework of diversity initiatives. Quest, 51, 310-327.

Fox, C. (1999). Women's Perceived Access to Elite Coaching Positions in Australian Sport. The Sport Educator, 11(2), 25-27.

Goodstein, J. (1994). Institutional pressures and strategic responsiveness: Employer involvement in work-family issues. Academy of Management Journal, 37, 350382.

Graham, M. (2004) in Stebbins, R. \& Graham, M. (eds), Volunteering as Leisure/Leisure as Volunteering: An International Assessment, CABI Publishing, Wallingford. (p.13)

Inglis, S., Danylchuk, K., \& Pastore, D. (2000). Multiple realities of women's work experiences in coaching and athletic management. Women in Sport and Physical Activity Journal, 9, 1-26. 
Kane, M. J., \& Disch, L. J. (1993). Sexual violence and the reproduction of male power in the locker room: The "Lisa Olson incident". Sociology of Sport Journal, 10(4), 331-352.

Kanter, R. M. (1977). Men and Women of the Corporation. New York: Basic.

Kerr, G., \& Marshall, D. (2007). Shifting the Culture: Implications for Female Coaches. Canadian Journal for Women in Coaching Online, 7 (4).

Knoppers, A. (1987). Gender and the Coaching Profession. Quest, 39(1), 9-22.

LeDrew, J. E., \& Zimmerman, C. (1994). Moving Towards an Acceptance of Females in Coaching. Physical Educator, 51(1), 6-14.

Leonard, J. S. (1989). Women and Affirmative Action. Journal of Economic Perspectives, 3(1), 61-75.

Lorber, J. (1994). Paradoxes of Gender. New Haven: Yale University Press.

Lovett, D. J., \& Lowry, C. D. (1994). "Good Old Boys" and "Good Old Girls" Clubs: Myth or Reality? Journal of Sport Management, 8(1), 27-35.

Luthans, F. (1988). Successful vs effective real managers. The Academy of Management, 11(2), 127-132.

Meyerson, D. E., \& Kolb, D. M. (2000). Moving out of the "armchair": Developing a framework to bridge the gap between feminist theory and practice. Organization 7, 553-571.

McKay, J. (1997) Managing Gender: Affirmative action and organizational power in Australian, Canadian, and New Zealand sport. State University of New York Press. 
Milliken, F.J., Martins, L., \& Morgan, H., (1998). Explaining organizational responsiveness to work-family issues: The role of human resource executives as issue interpreters. Academy of Management Journal, 41, 580-592.

Peters, M. A. (2006). Inquiry into women in sport and recreation in Australia. Bruce ACT: Australian Sports Commission.

Pini, B., Brown, K., \& Ryan, C. (2004). Women-only networks as a strategy for change? A case study from local government. Women in Management Review, 19(6), 286292.

Rao, A., Stuart, R., \& Kelleher, D. (Eds.). (1999). Gender at work: Organizational change for equality. West Hartford, CT: Kumarian.

Reynolds, M. (1991). Attracting and Retaining Female Coaches. Sports Coach, OctoberDecember, 3-7.

Roffey, K. (2001). Reasons for Shortages of Female Coaches. The Sport Educator, 13(2), $39-40$.

Schell, L. A., \& Rodriquez, S. (2000). Our sporting sisters: How male hegemony stratifies women in sport. Women in Sport and Physical Activity Journal, 9(1), 1534.

Schwalbe, M., Godwin, S., Holden, D., Schrock, D., Thompson, S., \& Wolkomir, M. (2000). Generic Processes in the Reproduction of Inequality: An Interactionist Analysis. Social Forces, 79(2), 419-452.

Shaw, S., \& Frisby, W. (2006). Can gender equity be more equitable?: Promoting an alternative frame for sport management research, education, and practice. Journal of Sport Management, 20, 483-509. 
Sheridan, A., \& Milgate, G. (2003). "She says, he says": women's and men's views of the composition of boards. Women in Management Review, 18(3), 147-154.

Stahura, K., \& Greenwood, M. (2001). Occupational employment patterns within women's intercollegiate athletics: Revisiting homologous reproduction. Research Quarterly for Exercise and Sport, 72(1), A-110.

Stangl, J. M., \& Kane, M. J. (1991). Structural Variables That Offer Explanatory Power for the Under-representation of Women Coaches Since Title IX: The Case of Homologous Reproduction. Sociology of Sport Journal, 8(1), 47-60.

Thorngren, C. M. (1990). A Time to Reach Out - Keeping the Female Coach in Coaching. Journal of Physical Education Recreation and Dance, March (1), 5760.

Ward, B. (2000). The Female Professor: a rare Australian species - the who and how. Paper presented at the 2nd European Conference on Gender Equality in Higher Education.

Weiss, M. R., \& Stevens, C. (1993). Motivation and Attrition of Female Coaches: An Application of Social Exchange Theory. The Sport Psychologist, 7(1), 244-261.

Whisenant, W. A., \& Pedersen, P. M. (2004). The influence of managerial activities on the success of intercollegiate athletic directors. American Business Review, 22(1), 21-26.

Whisenant, W. A., Vincent, J., Pedersen, P. M., \& Zapalac, R. (2007). An analysis of homologous reproduction in interscholastic athletics. [Electronic Version]. Advancing Women in Leadership Online Journal, 25. 
White, K. (2001). Women in the professoriate in Australia. International Journal of Organisational Behaviour, 3(2), 64-76. 